\title{
Affirmative Competence and Practices of Mental Health Professionals with LGB clients: An Ibero-American Study
}

\author{
Henrique Pereira' ${ }^{1}$ - Maria João Cunha ${ }^{1}$ Samuel Monteiro ${ }^{1} \cdot$ Graça Esgalhado $^{1} \cdot$ Rosa Marina Afonso $^{1}$. \\ Manuel Loureiro ${ }^{1}$
}

Received: 30 October 2016 / Accepted: 28 January 2019

○) Springer Science+Business Media, LLC, part of Springer Nature 2019

\begin{abstract}
There are not many studies about affirmative competence and practices among mental health professionals working with Lesbian, Gay, and/or Bisexual (LGB) clients. Thus, the objectives of this research are to assess the levels of affirmative competence and practices of professionals in Ibero-American countries. The sample consists of 630 mental health professionals from various countries whose ages range from 22 to 75 years old, with a mean age of 41.46 years. The study utilizes the following measures: a socio-demographic questionnaire, the Sexual Orientation Counselor Competency Scale, and the Affirmative Practice Questionnaire. Results show that mental health professionals who present higher levels of Affirmative Competence are those who have higher levels of education and training on LGBT topics, show left-wing political affiliations, self-identify as LGB, and have no religious affiliations. Regarding Affirmative Practices, it was found that single participants show lower practices, and more studies are needed to better understand this result. Regression models demonstrate that Affirmative Practices and Competences are predicted by the hypothesized variables, namely, religious and political beliefs, and training/education. Hence, this study indicates that mental health professionals could undergo some type of academic or professional training and/or possess experience in regard to working with LGB clients, in order to enhance their approach when working with this population.
\end{abstract}

Keywords Mental health professionals · Psychologists · Psychotherapists · LGB clients · Affirmative competence · Affirmative practice

\section{Introduction}

This article core issue is about affirmative competences (AC) and affirmative practices (AP) that can be seen as a set of attitudes and behaviors rather than specific techniques, such as to provide positive and respectful care to LGB clients (Travis 2011). Indeed, it is important to consider the interaction between social, cultural, contextual factors and sexual orientation when providing competent healthcare to LGB clients (APA 2012, 2015).

LGB people are identified as specifically vulnerable to health disparities, especially high rates of depression, mental distress, functional disability, substance use, and HIV

Henrique Pereira

hpereira@ubi.pt

1 Department of Psychology and Education, University of Beira Interior, Estrada do Sineiro, S/n, 6200-209 Covilha, Portugal risk (Fredriksen-Goldsen et al. 2011; Grant et al. 2010). Discrimination experienced by LGB people could be a barrier to the access of health and support services (Leonard 2002). We know now that it is imperative that providers of mental health have AC and AP (Lee and Quam 2013), and most therapists are probably not suitably trained to work with LGB clients (Carlson et al. 2013; Henke et al. 2009; Leonard 2002; Rock et al. 2010). Often, these issues are included in a single course on diversity, which provides an insufficient understanding regarding the experience of LGB clients intra-psychically and with respect to levels of social construction (Borges 2009). Therapists will be continually challenged, provoked, and educated by their clients on issues that still constitute one of the world's greatest and most sacred 'taboos': sexuality (Pope et al. 2000).

Sexuality is an extremely complex domain of human personality, which leads psychologists and mental health professional to focus on research and practices regarding 
human sexuality in general and homosexuality in particular (Vazquez-Rivera et al. 2014).

Historically, a series of socio-cultural and scientific events contributed to the emergence of a new approach called Gay Affirmative Therapy, which serves not only to challenge the causal factors associated with the expression of sexual orientation, but also provides clients with the best practices to guide those who have difficulty relating to their homosexuality and to help LGB clients accept their sexual orientation (APA 2012). The suffering of many LGB people is explained as a consequence of the social victimization to which they are subject, which, in turn, results in prejudice and discrimination. As a result, LGB people can be classified as an oppressed minority group (Moita 2001). Moleiro and Pinto (2009) state that this therapy celebrates and defends the authenticity and integrity of the rights of the LGB population, as well as their significant relationships. These ethical recommendations stress the importance that mental health professionals could recognize that their own attitudes and knowledge about LGB people's experiences are relevant to the therapeutic process and, therefore, could seek literature, specific training, and supervision in regard to the best practices when working with LGB clients (APA 2012, 2015).

Therefore, affirmative practices with LGB clients could adopt an approach based on normal, healthy expressions of human development, sexuality, relationships, and love. In addition, through policies and affirmative practices, mental health professionals must incentivize open and direct dialogue to support and facilitate the therapeutic process (Whitman and Bidell 2014). Furthermore, to effectively work with LGB clients, therapists need to be comfortable with their own sexual identities and be ready to examine their beliefs, feelings, and prejudices (Carroll 2010). Attitudes refers to the therapist's beliefs and ways of thinking about minorities, as well as their own prejudices and how they may affect the therapist-patient relationship. It also includes self-awareness and comfort or discomfort with the client and their cultural differences. Although there are numerous studies on the cultural competency model, very little consensus exists concerning the definition and importance of this model, due to the wide range of skills necessary to work with each culturally diverse population (Johnson 2013).

Many studies claim that psychologists and psychotherapists need to receive specific clinical training in order to develop effective counseling and therapy skills to work with LGB clients (Alderson 2004; Bernstein 2000; Bidell 2005, 2011; Godfrey et al. 2006; Grove 2009; Israel et al. 2011; Kocarek and Pelling 2003; Long and Serovich 2003; Matthews et al. 2005; McGeorge and Toomey 2013; Rutter et al. 2008). Nevertheless, this clear need for training does not appear in the ethical guidelines and skills of most current graduate programs in psychology (Graham et al.
2012). In fact, graduate psychology students report inadequate preparation during their training to meet the needs of LGB clients and no training on affirmative practices with LGB clients (Murphy et al. 2002; Rock et al. 2010).

Beliefs about the etiology of homosexuality (learned or an environmental individual choice) or uncontrollable (biological or genetic) are linked to greater rejection or acceptance of homosexuality, respectively (Haider-Markel and Joslyn 2008; Costa et al. 2015). Therefore, beliefs, acceptance, and feelings towards homosexuality seem to have a strong connection with the religious beliefs of each individual, since, in certain religions, homosexuality is seen as immoral and unacceptable (Brown and Henriquez 2008; Gusmano et al. 2002; Israel and Selvidge 2003). Political orientation also seems to have a strong role when we speak of acceptance and attitudes towards the LGB population (Weishut 2000; Brewer 2003; Brown and Henriquez 2008; Kreitzer et al. 2014), with more conservative people tending to be less accepting. These factors demonstrate the importance of exploring how this set of values may or may not influence the therapeutic process.

In the Ibero-American context, studies with therapists and clients show that although, in most cases, there was no explicit intention of changing homosexual orientation, implicitly this intent still exists in some situations (Moita 2001, 2006). This leads to the necessity of exploring which variables influence the therapeutic process and the therapist-client interaction with LGB people. Therefore, the objectives of this research are to assess the levels of affirmative competency and practices in a sample of mental health professionals from Ibero-America countries, in order to compare differences regarding gender, country of origin, spiritual beliefs, political and sexual orientation, age, education, marital status, and specific education in regard to LGB clients, with the aim of determining the predictive values between AC and AP, and this is the gap in knowledge that we are seeking to fill. Based on the above objective, the following hypothesis were formulated:

There would be a significant difference in $\mathrm{AC}$ and $\mathrm{AP}$ according to:

- Several sociodemographic characteristics (age, gender, marital status, sexual orientation, and country of origin); older, male, married, heterosexual, and Latin American professionals would have lower levels of AC and AP;

- Beliefs (religious and political); self-identified religious and right-wing mental health professionals would have lower levels of AC and AP;

- Training (formal education and training in LGBT issues); mental health professionals with more education and training in LGBT issues would have higher levels of AC and AP. 


\section{Method}

\section{Procedures}

This study was preliminary approved by the Ethics Committee of the University of Beira Interior (Portugal). Data collection took place from October 2014 to February 2015 and was aimed at mental health professionals from various Ibero-American countries (including Portugal, Brazil, Spain, Mexico, Argentina, Bolivia, and Paraguay, in addition to other, less represented in the sample, South America countries). We used the internet to disseminate all measures and contact mental health professionals from Ibero-American countries. Information about the study was disseminated through each country associations or professional orders, that work with LGB people mental health (e.g., psychologists, psychiatrists, psychotherapists, etc.), that voluntary disseminate it through the professional's mailing list. Participants responded to this online outreach through a linked website created for this specific purpose. A total of 3151 individual e-mails have been sent and 630 participants have voluntary answered (response rate near of 20\%). The dissemination of the questionnaires was carried out through two different web addresses, one in Portuguese language and the other in Spanish language (both intelligible for the Portuguese and Spanish language variants). Ethical and deontological issues, including informed consent and confidentiality were preserved. The study complied with all of the ethical principles established by the Portuguese Board of Psychologists, as well as the guidelines of the American Psychological Association. In accordance with the study description, and in order to clarify the research objectives participants were asked to read and agree to an informed consent waiver and to acknowledge their voluntary participation in the study, as well as to indicate that they are cognizant of any issues concerning confidentiality. Each participant was instructed to reply to the questionnaires individually, having been previously informed about the purpose and the objectives of the study. Inclusion/exclusion criteria included the following: to be a mental health related professional; to be over 18 years of age; to be a national of one of the eligible countries; to be a Portuguese and/or Spanish language(s) native speaker (Table 1 ).

\section{Measures}

We designed a socio-demographic questionnaire, in order to characterize the homogeneity/ heterogeneity of the study sample. Our questionnaire covers information on age, country of residence, gender, marital status, educational level, profession, religious beliefs, political orientation, and specific training on LGB issues, among other factors. To measure the AC of therapists toward LGB clients, we adapted "The Sexual Orientation Counselor Competency Scale" (Bidell 2005) to the Portuguese and Spanish versions, following Beaton et al. (2000) guidelines, which assesses the attitudes, skills, and knowledge of counselors working with LGB clients. It is a selfrated scale composed of 28 items, each rated on a Likert scale of 7 points, ranging from 1 ("Not true at all") to 7 ("Completely True"). Cronbach's alpha shows very good internal consistency $(\alpha=0.80)$ for the scale. This scale consists of three dimensions. The first, "Skills", includes eleven items focusing on LGB affirmative clinical work. The second dimension is "Consciousness of Behavior", which includes 10 items that examine LGB self-prejudice and stigmatization. Finally, the third dimension is "Knowledge", which consists of eight items that assess the knowledge of LGB psychosocial issues. From these three dimensions we derive a global measure of Competence, which results from the sum of all items of the scale. Some examples of scale items are: "At this point I do not have the training or the ability to support an LGB client", "The lifestyle of a LGB client is unnatural or immoral", and "There are psychosocial issues that have a different impact on the lives of gay men versus lesbians".

In order to measure affirmative practices with LGB clients, i.e. to evaluate the beliefs and behaviors of professionals working with this population, we adapted following the Beaton et al. (2000) guidelines the "Gay Affirmative Practice Scale", developed by Crisp (2002), to the Portuguese and Spanish versions. This questionnaire consists of 16 items rated on a Likert scale of 5 points, ranging from 1 ("never") to 5 ("Always"). The questionnaire is designed only to be completed by professionals who, at some point in their working lives have worked with LGB clients. As for the internal consistency of this instrument, Cronbach's alpha showed very good internal consistency ( $\alpha=0.83$ ). The scale consists of two dimensions. The first is behavior in practice with LGB clients, and the second concerns beliefs about practice with LGB clients (that are distinct from attitudes about gay and lesbian individuals). We designed a general measure of practices in order to better focus on the general objective of this research, which, in this case, is to assess the overall affirmative practices with LGB clients. Some examples of items appearing on this scale were: "I try to change the sexual orientation of my LGB clients", "I inform my LGB clients about the resources available in the LGB community", and "I show discomfort about LGB issues with my LGB clients". 
Table 1 Characteristics of the participants $(N=630)$

\begin{tabular}{|c|c|c|}
\hline Dimensions & $n$ & $\%$ \\
\hline \multicolumn{3}{|l|}{ Country } \\
\hline Portugal & 145 & 23 \\
\hline Brazil & 146 & 23.2 \\
\hline Spain & 120 & 19.1 \\
\hline Mexico & 59 & 9.3 \\
\hline Argentina & 42 & 6.7 \\
\hline Other countries—including Chile, Bolivia, Colombia, Paraguay, and Venezuela, among others & 118 & 18.7 \\
\hline \multicolumn{3}{|l|}{ Marital status } \\
\hline Married & 274 & 43.5 \\
\hline Single & 157 & 24.9 \\
\hline Emotionally committed relationship & 72 & 11.4 \\
\hline Divorced & 60 & 9.5 \\
\hline Civil union & 57 & 9 \\
\hline Widowed & 7 & 1.1 \\
\hline \multicolumn{3}{|l|}{ Educational levels (in the mental healthcare area) } \\
\hline Attended university & 94 & 14.9 \\
\hline Bachelor's degree (BSc) & 87 & 13.8 \\
\hline Post-graduate education (post graduate certification or a Master's) & 266 & 42.2 \\
\hline Doctorate & 160 & 25.4 \\
\hline Post-doctoral training & 14 & 2.2 \\
\hline \multicolumn{3}{|l|}{ Sexual orientation } \\
\hline Heterosexual & 534 & 84.8 \\
\hline Homosexual & 47 & 7.5 \\
\hline Bisexual & 45 & 7.1 \\
\hline \multicolumn{3}{|l|}{ Political orientation } \\
\hline Left-wing parties & 194 & 30.8 \\
\hline Center/left parties & 132 & 21 \\
\hline Centrist parties & 42 & 6.7 \\
\hline Center/right parties & 27 & 4.3 \\
\hline Right-wing parties & 24 & 3.8 \\
\hline Extreme left-wing parties & 15 & 2.4 \\
\hline Extreme right-wing parties & 3 & 0.5 \\
\hline No political orientation & 165 & 26.2 \\
\hline \multicolumn{3}{|l|}{ Training concerning issues of sexual orientation $(L G B)$ throughout their academic career } \\
\hline Have never undergone any training in this area & 385 & 61.1 \\
\hline Received some training at a very specific point in their academic career & 240 & 38.1 \\
\hline Have already worked with LGB clients in their practice & 468 & 74.9 \\
\hline
\end{tabular}

\section{Results}

The sample consists of 630 participants, who identify themselves as mental health professionals, from various IberoAmerican countries with language, cultural and historical bonds. Participant's ages range from 22 to 75 years old (mean $=41.46$ years, SD $=12.01$ ). The majority of professionals $417(66.2 \%)$ are female. When asked about their religious beliefs, the majority $(336,53.3 \%)$ of participants are religious.

We computed the total levels of AC and AP in order to facilitate data analysis. As can be seen in Table 2, the
Table 2 Results for affirmative competence and affirmative practices

\begin{tabular}{lll}
\hline & Affirmative competence & $\begin{array}{l}\text { Affirma- } \\
\text { tive } \\
\text { practices }\end{array}$ \\
\hline $\mathrm{N}$ & 630 & 468 \\
Mean & 145.67 & 69.27 \\
Median & 148 & 71 \\
Mode & 157 & 76 \\
Standard deviation & 18.38 & 8.64 \\
Minimum score & 74 & 32 \\
Maximum score & 184 & 80 \\
\hline
\end{tabular}


total mean of AC is approximately 145 . Given that the cutoff point for this scale is 112 , it can be said that participants present, on average, good levels of AC toward LGB clients. Regarding practices, results are similar. Since the cut-off point is 48 , and participants score above this value (mean $=69.27$ ), this reflects good general levels of affirmative practices. Thus, it can be said that, in general, the mental health professionals surveyed in the present study demonstrate positive AC and AP toward LGB clients.

When we analyze the results with respect to different age groups (under 40 and over 41 years of age), no statistically significant differences either in the AC Scale $(p=.315)$ or the Affirmative Practices Scale $(p=.442)$ are found. This is also the case when comparing men and women, since no statistically significant differences either for the AC Scale $(p=.481)$ or for Affirmative Practices Scale $(p=.258)$ are present. Despite the absence of significant differences, men scored slightly above women in both scales.

Statistically significant differences for the AC Scale $(p=.005)$ and the Affirmative Practices Scale $(\mathrm{p}=.055)$ are found when mental health professions have specific training on LGB issues. Therapists who possess specific training about LGB issues have higher scores on both scales, when compared to those who do not have training concerning LGB issues.

With regard to religious beliefs, the results show that statistically significant differences exist for both the AC Scale $(p<.001)$ and the Affirmative Practices Scale $(p=.049)$, indicating that mental health professionals who have no religious beliefs present higher levels of AC and AP.

Statistically significant differences in relation to levels of education were also found for the AC Scale $(p=.001)$. However, this was not the case for the Affirmative Practices Scale $(p=.559)$, whose results demonstrate no significant differences based upon levels of education. We can also see that therapists who have post-graduate certifications or degrees, demonstrate higher levels of $\mathrm{AC}$ when working with LGB clients. Political orientation was also explored, and statistically significant differences are seen for both scales $(p<.001)$, with left-wing oriented professionals scoring higher than those who identify politically with the right.

With regard to the sexual orientation of practitioners, we can see that there are statistically significant differences both in regard to the AC Scale $(p<.001)$ and the Affirmative Practices Scale $(p=.003)$. Self-identified homosexual and bisexual participants present higher scores on both scales, when compared to heterosexual participants. No statistically significant differences in both scales are found when comparing participants' countries of origin.

Finally, no statistically significant differences for marital status are found for the AC Scale $(p=.419)$. However, this is not the case for the Affirmative Practices Scale, where results show statistically significant differences $(p=.024)$ that indicate that married therapists show lower levels of $\mathrm{AC}$ and AP when working with LGB clients. Divorced participants score higher on the Affirmative Practices Scale. All of these results are shown in Table 3.

Using the linear regression model, the data show that there is a significant predictive value $(p<.001)$ between AC and AP with LGB clients (Tables 4, 5). Thus, it is possible to assert that mental health professionals who have $\mathrm{AC}$ will also have AP.

\section{Discussion}

Based on the overall results of this study, we can see that the mental health professionals surveyed do not have strongly preconceived beliefs about the LGB population. There are several important points to note concerning this study. The most apparent quality is the sample size $(N=630)$, which increases the confidence in the results of the study. In addition, the scales used show good to excellent reliability and validity. Therefore, this study has the potential to significantly influence the field of knowledge in this area.

According to the hypothesis formulated, our results do not indicate statistically significant differences between the two scales under study among the countries examined, although we would expect some cultural influence on participants' beliefs on a sensitive topic such as sexual orientation. Yet, these relatively homogeneous results can be attributed to the consequences of globalization, which creates the image of a more uniform world, not only in respect to politics and economics, but also in regard to culture (Frois 2004), science and academics. Nevertheless, regarding beliefs, it is well established in the literature that conservative religious beliefs are strongly associated with more negative, moralistic, and prejudiced views about matters concerning LGB people (Bowers et al. 2010; Hunsberger and Jackson 2005; Poteat and Mereish 2012; Whitley 2009). Our results illustrate the difficulty some therapists have in reconciling their religious beliefs with the posture of $\mathrm{AC}$ and $\mathrm{AP}$ with LGB clients. This is also the case for results with respect to political orientation, which concur with other studies that highlight that possessing left-wing political beliefs is associated with better competence and practices with LGB clients (Weishut 2000; Brewer 2003; Brown and Henriquez 2008; Kreitzer et al. 2014).

Our results relating to specific training in LGB issues are similar to those of other studies (Bidell 2012a, b; Israel and Hackett 2004; Matthews 2005; Rutter et al. 2008; Whitman and Bidell 2014). They emphasize the importance of specific training in LGB topics during the academic/training path of any mental health professional, since those who demonstrate higher AC and AP have undergone specific training on LGB issues. This is because professionals who have specific 
Table 3 Results for affirmative competence and practices between groups

\begin{tabular}{|c|c|c|c|c|c|c|}
\hline & \multicolumn{3}{|l|}{ Competence } & \multicolumn{3}{|l|}{ Practices } \\
\hline & $\mathrm{M}(\mathrm{SD})$ & $t(d f)$ & $p$ & $\mathrm{M}(\mathrm{SD})$ & $t(d f)$ & $p$ \\
\hline \multicolumn{7}{|l|}{ Age } \\
\hline$<40$ & $146.32(16.83)$ & $1.005(510)$ & .315 & $68.93(8.68)$ & $-0.770(453)$ & .442 \\
\hline$>41$ & $144.69(19.81)$ & & & $69.56(8.64)$ & & \\
\hline \multicolumn{7}{|l|}{ Gender } \\
\hline Female & $145.16(18.10)$ & $-0.705(519)$ & .481 & $68.92(9.04)$ & $-1.131(462)$ & .258 \\
\hline Male & 146.35 (18.89) & & & $69.88(7.81)$ & & \\
\hline \multicolumn{7}{|l|}{$L G B$ training } \\
\hline Yes & $148.63(18.92)$ & $2.852(519)$ & $.005 *$ & $70.20(8.47)$ & $1.921(465)$ & .055 \\
\hline No & $143.90(17.86)$ & & & $68.63(8.70)$ & & \\
\hline \multicolumn{7}{|l|}{ Religious beliefs } \\
\hline Yes & $142.58(20.78)$ & $-4.210(521)$ & $.000 * *$ & $68.55(9.29)$ & $-1.977(464)$ & $.049 *$ \\
\hline No & $149.26(14.43)$ & & & 70.14 (7.74) & & \\
\hline \multicolumn{7}{|l|}{ Level of education } \\
\hline University attendance & $140.13(22.22)$ & $4.071(5 ; 511)$ & $.001 * *$ & $67.80(10.25)$ & $0.787(5 ; 457)$ & .559 \\
\hline Bachelor's & $143.46(17.72)$ & & & $69.97(8.05)$ & & \\
\hline Post-graduate & $147.02(16.50)$ & & & $69.41(8.71)$ & & \\
\hline Ph.D. & $148.46(16.80)$ & & & 69.98 (7.39) & & \\
\hline Post-doctoral & $129.30(35.57)$ & & & $67.33(8.32)$ & & \\
\hline Other & $145.64(18.24)$ & & & $74()$. & & \\
\hline \multicolumn{7}{|l|}{ Political orientation } \\
\hline Extreme-left & $145.31(12.10)$ & $4.343(8 ; 512)$ & $.000 * *$ & $66.08(9.47)$ & $4.043(8 ; 456)$ & $.000 * *$ \\
\hline Left & $151.40(15.38)$ & & & $70.96(7.73)$ & & \\
\hline Center/left & $145.27(18.87)$ & & & $69.27(7.78)$ & & \\
\hline Centrist & $141.14(24.38)$ & & & 72.19 (7.37) & & \\
\hline Center/right & $145.30(18.32)$ & & & $70.84(8.44)$ & & \\
\hline Right & $134.90(21.51)$ & & & $65.11(9.52)$ & & \\
\hline Extreme-right & $123.33(8.33)$ & & & $54.67(14.01)$ & & \\
\hline No political affiliation & $143.01(18.82)$ & & & $68.36(9.53)$ & & \\
\hline Other & $141.21(14.33)$ & & & $65.89(8.14)$ & & \\
\hline \multicolumn{7}{|l|}{ Sexual orientation } \\
\hline Heterosexual & $144.02(18.22)$ & $14.989(2 ; 518)$ & $.000 * *$ & $68.71(8.74)$ & $5.773(2 ; 461)$ & $.003 *$ \\
\hline Bisexual & $156.56(12.62)$ & & & $72.43(6.01)$ & & \\
\hline Homosexual & $145.76(18.34)$ & & & $72.50(8.88)$ & & \\
\hline \multicolumn{7}{|l|}{ Country of origin } \\
\hline Portugal & $148.51(15.82)$ & $1.966(5 ; 513)$ & .082 & $70.45(7.15)$ & $0.887(5 ; 457)$ & .490 \\
\hline Brazil & $147.20(18.50)$ & & & $69.66(9.60)$ & & \\
\hline Spain & $146.41(16.49)$ & & & $69.00(8.33)$ & & \\
\hline Mexico & $142.35(22.01)$ & & & $68.74(8.77)$ & & \\
\hline Argentina & $144.33(18.91)$ & & & $67.17(7.19)$ & & \\
\hline Other & $141.89(19.86)$ & & & $68.73(9.78)$ & & \\
\hline \multicolumn{7}{|l|}{ Marital status } \\
\hline Single & $146.26(18.35)$ & $1.008(6 ; 517)$ & .419 & $67.32(9.33)$ & $2.452(6 ; 461)$ & $.024 *$ \\
\hline Married & $144.16(20.15)$ & & & $69.25(8.48)$ & & \\
\hline Civil union & $148.67(14.16)$ & & & $70.26(8.04)$ & & \\
\hline Divorced/separated & $146.51(16.90)$ & & & $72.59(6.94)$ & & \\
\hline Widowed & $146.20(12.97)$ & & & $68.67(12.61)$ & & \\
\hline Emotional commitment & $146.26(15.61)$ & & & $70.21(8.19)$ & & \\
\hline Other & $164.33(6.66)$ & & & $72.50(0.71)$ & & \\
\hline
\end{tabular}

$* \leq .5 ; * * \leq .001$ 
Table 4 Results for the linear regression model (affirmative competence)

\begin{tabular}{lrl}
\hline Variable & \multicolumn{1}{l}{ Beta } & $p$ \\
\hline Affirmative competence & & \\
Age & -0.037 & .411 \\
Gender & 0.022 & .619 \\
Marital status & 0.003 & .952 \\
Country of residence & -0.123 & $.006^{*}$ \\
Sexual orientation & 0.180 & $.000^{* *}$ \\
Religious beliefs & 0.140 & $.002^{*}$ \\
Political orientation & -0.101 & $.023^{*}$ \\
Education & 0.086 & $.050^{*}$ \\
Training in LGB issues & -0.146 & $.001^{*}$ \\
\hline
\end{tabular}

$* \leq .5 ; * * .001$

Table 5 Results for the linear regression model (affirmative practices)

\begin{tabular}{lrl}
\hline Variable & Beta & $p$ \\
\hline Affirmative practices & & \\
Age & 0.063 & .196 \\
Gender & 0.054 & .262 \\
Marital status & 0.099 & $.039^{*}$ \\
Country of residence & -0.089 & .067 \\
Sexual orientation & 0.130 & $.007^{*}$ \\
Religious beliefs & 0.035 & .470 \\
Political orientation & -0.082 & .094 \\
Education & 0.025 & .602 \\
Training in LGB issues & -0.104 & $.030^{*}$ \\
\hline
\end{tabular}

$* \leq .5 ; * * .001$

training about LGB clients have more knowledge and skills in relation to the subject. In turn, this enables them to be potentially more effective when working directly with this population.

LGB people, in addition to confronting the same societal difficulties heterosexual people face, are also subject to additional discrimination, oppression, stigma, and isolation. It is naturally difficult for any individual who has suffered this type of homophobia to confide in any therapist, as there is no guarantee of openness and empathy. Therefore, the challenges and characteristics of conducting psychological consultations with LGB clients are extremely relevant to any mental health professional, in order to allow clients to access a non-discriminatory professional practice. Thus, intervention with LGB clients implies an affirmative approach that recognizes the existence of social discrimination against sexual minorities and seeks permanent training to creatively and actively deal with the specific issues that LGB clients may present. In the interest of maximizing the chances of success, it is essential that clinicians are able to respond to the high expectations that LGB clients can bring to the therapeutic process (Menezes and Costa 1992).

Among the various qualities of competence described as fundamental for mental health professionals working with LGB clients, we highlight the following: the capacity to analyze their own values, attitudes, and lifestyle; knowledge of the stressors common to LGB people; knowledge about developmental models of homosexual identity; and expertise on how to appropriately carry out differential diagnoses (Moita 2001). Previous research highlights the negative impacts that a lack of education on LGB issues can have on mental health professionals' clinical approaches and practices when working with LGB patients. Due to this lack of awareness, in some cases, therapists mistakenly report that there are no differences between their approaches to heterosexual and homosexual clients (Biechele 1996). In studies where the experimental design allows for the correlation of the assessment of therapists' affirmative practices and their sexual identity, therapists who score more positively are gay men, and heterosexual females, and this is consistent with our results. Straight male therapists are most likely to reject LGB clients (Sorensen and Roberts 1997; Liddle 1997) and similarity in terms of sexual orientation between clients and therapists is sometimes associated with a positive assessment. However, several authors point out that this similarity is neither necessary, nor a guarantee of a positive assessment. The kind of treatment practices therapists implement and the perception that clients have of therapists' interpretation of their sexual orientation are more important than the sexual orientation of the therapist (Liddle 1997; Cohen and Stein 1986).

Overall, we can state that our hypothesis were confirmed, particularly the following parameters: mental health professionals who present higher levels of AC are those who have higher levels of education and training on LGBT topics, show left-wing political affiliations, self-identify as LGB, and have no religious affiliations. Regarding Affirmative Practices, it was found that single participants show lower practices, and more studies are needed to better understand this result. Finally, regression models demonstrate that Affirmative Practices and Competences are influenced by the hypothesized variables, namely, religious and political beliefs, and training/education. On the one hand, positive assessments may be associated with other variables, such as community participation, social support or personality, and legislative frameworks. However, on the other hand, the existence of discrimination-free courses and programs in Universities can be seen as an instrumental driver of affirmative attitudes directly contributing to the personal happiness, confidence, and security of LGB clients.

This study was conducted in Ibero-American countries, where Catholicism is the most widespread religion, and where the secular character of the state, ratified in most 
constitutional laws, is actually influenced by conservative values. Nonetheless, results showed the effects of religiosity and conservative on competencies and practices. These results are consistent with those obtained in other studies (Schwartz 2010) that identified religious and political ideology as the most powerful predictor of attitudes toward LGB people. One possible explanation for these discrepancies is the fact that the legal context for LGB rights in most Latin countries was historically built on very light anti-LGB policies after the decriminalization of homosexuality.

There are three potential limitations that are important to discuss. While our intention was to recruit a sample that would allow us to describe and generalize the AC and AP of the entire population of psychotherapists, the controversial nature of the subject may have influenced those who chose to participate. Therefore, it is not clear if our results reflect the general beliefs of all mental health professionals. Another possible limitation is the fact that the scales used to measure $\mathrm{AC}$ and $\mathrm{AP}$ of participants focus on perceptions, which is not the same as measuring their actual competence and practices. Therefore, it is possible that the participants believe that they are competent and have affirmative practices in the treatment of LGB clients; however, in clinical practice this may not be the case. Thus, it is important for future research to determine the real level of competence and clinical practice of mental health professionals when working with LGB clients. One way to overcome this limitation would be to interview LGB clients about the quality of services they received and how they would rate their therapists. The scarcity of published articles on this topic and the lack of focus on affirmative intervention with sexual minorities constitute a limitation as well. In fact, since only about $2 \%$ of studies place a significant focus on LGB clients (Alderson 2004), our research is an important contribution to this field.

Our research forces us to recall some of the relevant ethical principles on the issue of sexual orientation developed by the American Psychological Association (2000) that will be very important to be self-analyzed and taken in consideration by mental health professionals. These principles address attitudes towards homosexuality and bisexuality, relationships and families, diversity, and education. Furthermore, these principles indicate that mental health professionals ought to understand that homosexuality and bisexuality are not indicators of mental illness and could seek to understand how various forms of social stigma (e.g. prejudice, discrimination, and violence) may endanger the mental health and well-being of LGB clients. In addition, therapists could seek to understand how inaccurate and prejudiced views about homosexuality and bisexuality may affect their client in terms of their treatment and the therapeutic process and may seek to understand and respect the importance of relationships for LGB people. Finally, mental health professionals could support education and training on issues related to sexual orientation, seeking to increase their knowledge about these issues through continuous training and familiarity with relevant clinical and educational resources in the area of mental health in the LGB community.

There are many studies that suggest that therapists without any special training or without intervention experience in regard to LGB clients may be encouraged to seek further training to increase their effectiveness when working with LGB individuals (Lytle et al. 2014). This research emphasizes the necessity of training on LGB issues for mental health professionals, supervisors, therapists, administrative staff, and other service providers, even apart from mental health professionals. This type of training can be particularly useful in creating an organizational climate that meets the needs of LGB clients. Since counseling is not something that happens just between two people but is instead a social institution embedded in the culture of industrialized and modern societies (McLeod 2003), for the therapeutic process to be effective, it is important that mental health professional feel confident in their abilities to work with this population in particular. In turn, this leads us to believe that institutions of higher education, which are responsible for developing curricula for mental health students, could provide the theoretical groundwork to understand AC and AP, in order to allow future professionals to acquire counseling skills, to work on self-consciousness, to explore professional issues, and to receive supervised practice on issues related to LGB clients.

\section{Compliance with Ethical Standards}

Conflict of interest The authors report no interests that relate to this article that could be construed as a conflict of interest.

\section{References}

Alderson, K. G. (2004). A different kind of 'outing': Training counsellors to work with sexual minority clients. Canadian Journal of Counselling, 38(3), 193-210.

American Psychological Association (APA). (2000). Guidelines for psychotherapy with lesbian, gay and bisexual clients. Retrieved on May 20 from http://www.apa.org/pi/lgbc/publications/guide lines.html.

American Psychological Association (APA). (2012). Guidelines for psychological practice with lesbian, gay, and bisexual clients. American Psychologist, 67, 10-42. https://doi.org/10.1037/a0024 659.

American Psychological Association (APA). (2015). Guidelines for psychological practice with transgender and gender nonconforming people. American Psychologist, 72, 832-864. https://doi. org/10.1037/a0039906.

Beaton, D. E., Bombardier, C., Guillemin, F., \& Ferraz, M. B. (2000). Guidelines for the process of cross-cultural adaptation of self-report measures. Spine, 25(24), 3186-3191. https://doi. org/10.1097/00007632-200012150-00014. 
Bernstein, A. C. (2000). Straight therapists working with lesbians and gays in family therapy. Journal of Marital and Family Therapy, 26(4), 443-454.

Bidell, M. (2005). The sexual orientation counselor competency scale: assessing attitudes, skills, and knowledge of counselors working with lesbian, gay, and bisexual clients. Counselor EducaUon \& Supervision, 44, 267-279.

Bidell, M. (2011). Examining school counseling students multicultural and sexual orientation competencies through a cross-specialization comparison. Journal of Counseling \& Development, 90, 200-207.

Bidell, M. P. (2012a). Addressing disparities: The impact of a lesbian, gay, bisexual, and transgender graduate counselling course. Counselling and Psychotherapy Research Journal, 13, 1-8. https://doi. org/10.1080/14733145.2012.741139.

Bidell, M. P. (2012b). Examining school counseling students' sexual orientation and multicultural competencies through a cross-specialization comparison. Journal of Counseling \& Development, 90, 200-207.

Biechele, U. (1996). Psychoterapy for lesbian and gay clients: A regional survey. The Association of Lesbian and Gay Psychologists Europe Newsletter, 5(2), 14-16.

Borges, K. (2009). Terapia Afirmativa: uma introdução à psicoterapia dirigida a gays. Brasil: Edições GLS: lésbicas e bissexuais.

Bowers, R., Minichiello, V., \& Plummer, D. (2010). Religious attitudes, homophobia, and professional counseling. Journal of LGBT Issues in Counseling, 4, 70-91.

Brewer, P. (2003). Values, political knowledge, and public opinion about gay rights: A framing-based account. Public Opinion Quarterly, 67(2), 173-201

Brown, M., \& Henriquez, E. (2008). Socio-demographic predictors of attitudes towards gays and lesbians. Individual Differences Research, 6(3), 193-202.

Carlson, T. S., McGeorge, C. R., \& Toomey, R. B. (2013). Establishing the validity of the lesbian, gay, and bisexual affirmative training inventory: Assessing the relationship between affirmative training and clinical competence. Journal of Marital and Family Therapy, $39,209-222$.

Carroll, L. (2010). Counselling Sexual and Gender Minorities. Columbus: Merrill.

Costa, P. A., Pereira, H., \& Leal, I. (2015). "The Contact Hypothesis" and Attitudes Toward Same-Sex Parenting. Sexuality Research and Social Policy, 12(2), 125-136.

Cohen, C., \& Stein, T. (1986). Reconceptualizing individual psychotherapy with gay men and lesbians. In T. Stein \& C. Cohen (Eds.), Contemporary perspectives on lesbians and gay men (pp. 27-54). New York: Plenum

Crisp, L. C. (2002). Beyond Homophobia: Development and Validation of the Gay Affirmative Practice Scale (Dissertation). University of Texas at Austin, Austin, Texas, USA.

Fredriksen-Goldsen, K. I., Kim, H.-J., Emlet, C. A., Muraco, A., Erosheva, E. A., Hoy-Ellis, C. P.,.. . Petry, H. (2011). The aging and health report: Disparities and resilience among lesbian, gay, bisexual, and transgender older adults. Seattle, WA: Institute for Multigenerational Health. Retrieved from http://caringandaging. org/wordpress/wp-content/uploads/2012/10/Full-report10-25-12. pdf.

Fróis, kP. (2004). Globalização e cultura a identidade no mundo de iguais. Cadernos de pesquisa interdisciplinar em Ciências Humanas, 5, 62

Godfrey, K., Haddock, S. A., Fisher, A., \& Lund, L. (2006). Essential training components of curricula for preparing therapists to work with lesbian, gay, and bisexual clients: A delphi study. Journal of Marital and Family Therapy, 32(4), 491-504.
Graham, S. R., Carney, J. S., \& Kluck, A. S. (2012). Perceived competency in working with LGB clients: Where are we now? Counselor Education and Supervision, 51(1), 2-16.

Grant, J. M., Kosovich, G., Frazer, M. S., \& Bjerk, S. \& SAGE. (2010). Outing Age 2010: Public policy issues affecting gay, lesbian, bisexual and transgender elders. Retrieved from http://www. thetaskforce.org/downloads/reports/reports/outingage_final.pdf.

Grove, J. (2009). How competent are trainee and newly qualified counsellors to work with lesbian, gay, and bisexual clients and what do they perceive as their most effective learning experiences? Counselling and Psychotherapy Research, 9(2), 78-85.

Gusmano, M., Schlesinger, M., \& Thomas, T. (2002). Policy feedback and public opinion: The role of employer responsibility in social policy. Journal of Health Politics, Policy and Law, 27(5), 731-772.

Haider-Markel, D. P., \& Joslyn, M. R. (2008). Beliefs about the origins of homosexuality and support for gay rights. Public Opinion Quarterly, 72, 291-310.

Henke, T., Carlson, T. S., \& McGeorge, C. R. (2009). Homophobia and clinical competency: An exploration of couple and family therapists' beliefs. Journal of Couple and Relationship Therapy, $8(4), 325-342$.

Hunsberger, B., \& Jackson, L. M. (2005). Religion, meaning, and prejudice. Journal of Social Issues, 61, 807-826.

Israel, T., \& Hackett, G. (2004). Counselor education on lesbian, gay and bisexual issues: Comparing information and attitude exploration. Counselor Education and Supervision, 43, 179-191.

Israel, T., \& Selvldge, M. (2003). Contributions of multicultural counseling to counselor competency with lesbian, gay, and bisexual clients. Journal of Multicultural Counseling and Development, 31, 84-97.

Israel, T., Walther, W., Gortcheva, R., \& Perry, J. (2011). Policies and practices for LGBT Clients: Perspectives of mental health services administrators. Journal of Gay \& Lesbian Mental Health, $15,152-168$.

Johnson, S. D. (2013). Assessing Self-Efficacy of Cultural Competence with Lesbian, Gay, and Bisexual Clients: A Comparison of Training Methods with Graduate Social Work Students (Dissertation). University of Kentucky, Lexington, Kentucky, USA.

Kocarek, E., \& PeHlng, J. (2003). Beyond knowledge and awareness: Enhancing counselor skills for work with gay, lesbian, and bisexual clients. Journal of Multicultural Counseling and Development, $31,99-112$.

Kreitzer, R., Hamilton, A., \& Tolbert, C. (2014). Does policy adoption change opinions on minority rights? The effects of legalizing same-sex marriage. Political Research Quarterly, 67, 795-808.

Lee, M. G., \& Quam, J. K. (2013). Comparing supports for LGBT aging in rural versus urban areas. Journal of Gerontological Social Work, 56(2), 112-126.

Leonard, W. (2002). What's the difference? Health issues of major concern to gay, lesbian, bisexual, transgender and intersex (GLBTI). In Victorians: research paper. Melbourne (AU): Ministerial Advisory Committee on Gay and Lesbian Health, Victorian Government Department of Human Services.

Liddle, B. (1997). Gay and lesbians client's selection as therapists and utilization of therapy. Psychotherapy, 34(1), 11-18.

Long, J. K., \& Serovich, J. M. (2003). Incorporating sexual orientation into MFT training programs: Infusion and inclusion. Journal of Marital and Family Therapy, 29(1), 59-67.

Lytle, M. C., Vaughan, M. D., Rodriguez, E. M., \& Shmerler, D. L. (2014). Working with LGBT individuals: Incorporating positive psychology into training and practice. Psychology of Sexual Orientation and Gender Diversity, 1(4), 335-347. https://doi. org/10.1037/sgd0000064. 
Matthews, C. (2005). Infusing lesbian, gay, and bisexual issues into counselor education. Journal of Humanistic Counseling, Education \& Development, 44, 168-184.

Matthews, C., Selvidge, M., \& Fisher, K. (2005). Addictions counselors' attitudes and behaviors toward gay, lesbian, and bisexual clients. Journal of Counseling and Development, 83, 57-65.

McGeorge, T., \& Toomey, R. (2013). Establishing the validity of the affirmative training inventory: assessing the relationship between lesbian, gay, and bisexual affirmative training and students' clinical competence. Journal of Marital and Family Therapy, 39(2), 209-222.

McLeod, J. (2003). An introduction to counselling. London: Open University Press.

Menezes, I., \& Costa, M. (1992). Amor entre Iguais: A psicoterapia da diferença. Cadernos de Consulta Psicológica, 8, 79-84.

Moita, G. (2001). Discursos sobre a Homossexualidade no Contexto Clínico: A Homossexualidade de dois lados do espelho (Dissertação). Universidade do Porto. Porto: Instituto de Ciências Biomédicas de Abel Salazar.

Moita, G. (2006). A patologização da diversidade sexual: Homofobia no discurso de clínicos. Revista Crítica de Ciências Sociais, 76, $53-72$.

Moleiro, C., \& Pinto, N. (2009). Diversidade e Psicoterapia: Expectativas e Experiências de pessoas LGBT acerca das Competências Muticulturais de Psicoterapeutas. Ex Aequo, 20, 159 - 172.

Murphy, J. A., Rawlings, E. I., \& Howe, S. R. (2002). A survey of clinical psychologists on treating lesbian, gay, and bisexual clients. Professional Psychology: Research and Practice, 33, 183-189.

Pope, K. S., Sonne, J. L., \& Holroyd, J. (2000). Sexual feelings in psychotherapy. Washington: American Psychological Association.

Poteat, V. P., \& Mereish, E. H. (2012). Ideology, prejudice, and attitudes toward sexual minority social policies and organizations. Political Psychology, 33, 211-224.

Rock, M., Carlson, T. S., \& McGeorge, C. R. (2010). Does affirmative training matter? Assessing CFT students' beliefs about sexual orientation and their level of affirmative training. Journal of Marital and Family Therapy, 36(2), 171-184.
Rutter, P. A., Estrada, D., Ferguson, L. K., \& Diggs, G. A. (2008). Sexual orientation and counselor competency: The impact of training on enhancing awareness, knowledge and skills. Journal of LGBT Issues in Counseling, 2, 109-125.

Schwartz, J. (2010). Investigating differences in public support for gay rights issues. Journal of Homosexuality, 57(6), 748-759. https:// doi.org/10.1080/00918369.2010.485875.

Sorensen, L., \& Roberts, S. (1997). Lesbian uses of and satisfaction with mental health services: Results from boston lesbian health project.. Journal of Homosexuality, 33(1), 35-49.

Travis, L. A. (2011). What you should know about LGBT older adults. Elder Care: A resource for interprofessional providers. Retrieved from https://nursingandhealth.asu.edu/files/ors/aging/providersh eets/lgbt.pdf.

Vázquez-Rivera, M., Martínez-Taboas, A., Toro-Alfonso, J., Francia, M., Nazario-Serrano, J., Lespier, Z., \& ... Santiago, G. (2014). Estándares para el Trabajo e Intervención en Comunidades Lesbianas, Gay, Bisexuales e Identidades Trans (LGBT). Retrieved from http://www.iniciativacomunitaria.weebly.com/uploa ds/2/5/6/2/2562722/estandares_para_el_trabajo_e_intervenci on_en_comunidades_lesbianas_gay_bisexual_y_transgeneros.pdf.

Weishut, D. (2000). Attitudes toward homosexuality: An overview. Israel Journal of Psychiatry and Related Sciences, 37(4), 308-319.

Whitley, B. E. Jr. (2009). Religiosity and attitudes toward lesbians and gay men: A meta-analysis. International Journal for the Psychology of Religion, 19, 21-38.

Whitman, J. S., \& Bidell, M. P. (2014). Affirmative lesbian, gay, and bisexual counselor education and religious beliefs: How do we bridge the gap? Journal of Counseling \& Development, 92, 162-169.

Publisher's Note Springer Nature remains neutral with regard to jurisdictional claims in published maps and institutional affiliations. 